\title{
Sutureless Aortic Valves in combined procedures: a useful tool in the armamentarium of cardiac surgeons
}

\author{
Steffen Pfeiffer, Ferdinand Vogt, Joachim Sirch, Theodor Fischlein, Giuseppe Santarpino* \\ From World Society of Cardiothoracic Surgeons 25th Anniversary Congress, Edinburgh \\ Edinburgh, UK. 19-22 September 2015
}

\section{Background/Introduction}

Following the encouraging preliminary results, sutureless aortic valve implantation is performed in a growing number of patients as it makes minimally invasive surgery easier.

\section{Aims/Objectives}

On the other hand, less data are available on the performance of sutureless aortic valves in combined or complex procedures.

\section{Method}

Between May 2010 and May 2015, 319 patients (age $77.4 \pm 5$ years, female 169 (53\%) underwent aortic valve replacement with a sutureless bioprosthesis in our institution. Of them, 25 were operated upon as REDO (10 with a degenerated aortic bioprosthesis and/or 15 with previous $C A B G$ ) or as combined procedures (114 Patients, Table 1). In-hospital and follow up clinical and echocardiographic data were collected for all patients and here reported for the combined procedures.

\section{Results}

Mean logistic EuroScore was $14.7 \pm 12 \%$. The patients received a size $S(n=4), M(n=40), L(n=53)$ or XL $(\mathrm{n}=17)$ prosthesis. Mean aortic cross-clamp time and cardiopulmonary bypass time were $55.3 \pm 21$ and $88.8 \pm$ 29 minutes, respectively. In-hospital mortality was $6.1 \%$. We recorded 15 pacemaker implantations (13.1\%). At follow-up ( $27 \pm 24$ months), we observed 2 pts. with endocarditis needing reoperation, 1 of these died postoperatively. Mean transprosthetic gradients were $13.4 \pm 5$,

Department of Cardiac Surgery - Paracelsus Medical University Nuremberg Germany 